Flow of Gases Through Porous Media

By Dr. P. C. Carman. Pp. ix +182. (London: Butterworths Scientific Publications; New York: Academic Press, Inc., 1956.) 30s.

T $\mathrm{T}$ is some twenty years since Dr. P. C. Carman $I$ suggested the permeability method for the measurement of the surface area of fine particles such as cement. During these years the range of interest in the flow of fluids through porous media has increased considerably, and in this book he has presented a concise account of the subject, including the recent work on gas diffusion and separation.

The primary aim of the book is to present a quantitative account of the flow process when a gas enters or passes through porous media. The theme of the book is a discussion of the Kozeny-Carman equation for the flow in such systems, and one of the great merits of the text is that the writer has explained in detail the limitations of this approach and the consequent reasons for its failure in some instances.

Chapter 1 contains a formal presentation of the Carman equation as developed for unconsolidated media, and in Chapter 4 the application of this equation for measurement of particle surface is given. Of greater interest is the discussion in Chapter 2 of the influence of abnormal pore texture, the distribution of pore size and the problem of flow through consolidated media.

Chapter 3 covers slip flow and Knudsen flow and a short account of diffusion in porous media. Chap. ters 5 and 6 contain an account of more recent work on the flow of sorbable gases, leading to a discussion on surface diffusion and gas separation processes. Finally, Chapter 7 covers the transition zone to turbulent flow and an introduction to the conditions of fluidization.

This is a scholarly text written by an acknowledged authority in this field, and it will be welcomed by all whose activities so much as touch on this subject. The book as written has rather a terse style, and a general introduction, particularly to Chapter 1 , would have been of value to the more general reader.

\section{Reduction with Complex Metal Hydrides}

By Norman G. Gaylord. Pp. xvi+1046. (New York: Interscience Publishers, Inc.; London : Interscience Publishers, Ltd., 1956.) 15 dollars.

7 HIS book, which started in 1951 as a review article on reductions with lithium aluminium hydride, is a comprehensive survey of the preparation, properties and uses of all the complex metal hydrides known up to the end of 1953 . The reactions of these hydrides with inorganic as well as organic compounds are described. Then there is a useful goneral discussion of reduction of organic compounds with complex metal hydrides: stereochemical features and analogies with Grignard reactions are reviewed. Each functional group has a chapuer to itself, with full references and tables giving substance reduced, product and yicld. In addition, the more interesting cases are described in fair detail with supporting formulæ and reacition schemes.

A very considerable number of the compounds mentioned are from the chemistry of natural products. The collecting together of so many examples will be of particular value to those investigating steroids. The information is set out in a very acceptable form, easy to follow. There ane very few mistakes, either chemical or typographical. It is a pity that throughout the book aluminium is spelt aluminum.

The book of this size and scope, which could so easily have been little more than a catalogue, is interesting and informative. It gives a balanced view of this extraordinarily fertile field and will doubtless stimulate further research in both in. organic and organic chemistry. E. E. TURNer

\section{Theory of Combustion Instability in Liquid Pro-} pellant Rocket Motors

By Luigi Crocco and Sin-i Cheng. (Agardograph, No. 8.) Pp. viii +200 . (London: Butterworths Scientific Publications; New York: Interscience Publishers, Inc., 1956. Published for and on behalf of the Advisory Group for Aeronautical Research and Development, North Atlantic Treaty Organization.) $37 s .6 d . ; 5.25$ dollars.

A LIQUID-PROPELLAN'T rocket motor is a A complicated system in which fuel and oxidizer are pumped through a perforated injector plate, combined in a combustion chamber and accelerated to supersonic exit-speeds in a Laval nozzle. This book is a compendium of theoretical considerations (related only perfunctorily to experiment) on the problem of understanding and learning to avoid such instabilities of the system as lead to oscillations of an organized character in the pressure and temperature in the combustion chamber; these can be responsible for mechanical or thermal failure of components. 'Chugging', or low-frequency instability, is ascribed to an interaction between the time-lag for change in injection-rate to produce changes in combustion-rate, the time-lag for these changes to evacuate the chamber to a different pressure, and the time-lag for this to affect the injection-rate through the equations of the pumping system. The equations are treated, in addition, for the case of a servomechanical control, which feeds back signals from the combustion chamber into the fuel flow-line, and for the case when the combustion time-lag itself varies with chamber pressure, which can lead to additional instability.

'Screaming', or high-frequency instability, is ascribed to the interaction of factors such as these with the normal modes of oscillation of the gas in the combustion chamber. Only 'Iongitudinal' modes (with motion along the axis) are here treated, although the authors admit that transverse and rotary 'sloshing' modes should also be considered important, as more recent work has, in fact, emphasized.

M. J. LIMHTHILL

\section{Atomic Physics}

An Atomic Description of Physical Phenomena. By Prof. Gaylord P. Harnwell and Prof. William E. Stephens. (International Series in Pure and Applied Physics.) Pp. $\mathbf{x}+401$. (London: McGraw-Hill Publishing Company, Ltd., 1955.) $60 s$.

7 HIS book exhibits the difference between the methods of teaching in American and British universities. It is based on a course of lectures given by the authors to first-year postgraduate students at the University of Pennsylvania. The standard is suitable for British undergraduates in their final year; but the book would be expensive for students here at $60 \mathrm{~s}$. The nearest equivalent published in Britain is Max Born's "Atomic Physics".

D. F. Johnston 